\title{
Loss of liver-intestine cadherin in human intrahepatic cholangiocarcinoma promotes angiogenesis by up-regulating metal-responsive transcription factor-1 and placental growth factor
}

\author{
MASAAKI TAKAMURA ${ }^{1}$, SATOSHI YAMAGIWA ${ }^{1}$, TOSHIFUMI WAKAI ${ }^{2}$, YASUSHI TAMURA ${ }^{1}$, \\ HIROTERU KAMIMURA ${ }^{1}$, TAKASHI KATO ${ }^{3}$, ATSUNORI TSUCHIYA ${ }^{1}$, YASUNOBU MATSUDA ${ }^{1}$, \\ YOSHIO SHIRAI ${ }^{2}$, TAKAFUMI ICHIDA ${ }^{4}$, YOICHI AJIOKA ${ }^{3}$ and YUTAKA AOYAGI ${ }^{1}$ \\ ${ }^{1}$ Division of Gastroenterology and Hepatology, ${ }^{2}$ Division of Digestive and General Surgery and ${ }^{3}$ Division of Molecular \\ and Diagnostic Pathology, Niigata University Graduate School of Medical and Dental Sciences, Niigata; ${ }^{4}$ Division of \\ Gastroenterology and Hepatology, Juntendo University School of Medicine, Shizuoka Hospital, Izunokuni, Japan
}

Received July 15, 2009; Accepted September 7, 2009

DOI: 10.3892/ijo_00000495

\begin{abstract}
Liver-intestine cadherin (LI-cadherin) represents a novel type of cadherin within the cadherin superfamily that comprises seven cadherin repeats and a short cytoplasmic domain. In this study, we first examined LI-cadherin expression immunohistochemically in 34 specimens of human intrahepatic cholangiocarcinoma (ICC). LI-cadherin expression was positive (defined as positivity in $\geq 10 \%$ of cells) in 18 of the ICCs $(52.9 \%)$. LI-cadherin negativity was significantly correlated with tumor dedifferentiation $(\mathrm{P}=0.026)$ and vascular invasion $(\mathrm{P}=0.015)$. The cumulative survival rate of patients with LI-cadherin-negative ICC was significantly shorter than that of patients with LI-cadherinpositive ICC $(\mathrm{P}=0.021)$. Multivariate analysis identified the extent of LI-cadherin staining as an independent prognostic factor for ICC survival ( $\mathrm{P}=0.027)$. Next, to elucidate the mechanism of loss of LI-cadherin-mediated aggressiveness
\end{abstract}

Correspondence to: Dr Masaaki Takamura, Division of Gastroenterology and Hepatology, Niigata University Graduate School of Medical and Dental Sciences, 757 Asahimachi-dori 1, Chuo-ku, Niigata 951-8510, Japan

E-mail: atmc@hotmail.co.jp

Abbreviations: ICC, intrahepatic cholangiocarcinoma; LIcadherin, liver-intestine cadherin; siRNA, small interfering RNA; MTF-1, metal-responsive transcription factor-1; PlGF, placental growth factor; MF, mass-forming; PI, periductal infiltrating; IG, intraductal growth; MVD, microvessel density; PCR, polymerase chain reaction; VEGF, vascular endothelial growth factor; GAPDH, glyceraldehyde-3-phosphate dehydrogenase

Key words: cadherin-17, vascular invasion, prognostic factor, siRNA, microarray in ICC, we knocked down LI-cadherin expression in an ICC cell line using small interfering RNA (siRNA) technology, and screened for genes that were expressed differentially between these cells and ICC cells transfected with scrambled siRNA using microarray analysis with real-time polymerase chain reaction confirmation. Among 21 identified genes, we focused on metal-responsive transcription factor-1 (MTF-1), whose target genes might contribute to tumor aggressiveness. Expression of placental growth factor (PlGF), one of the MTF-1 target genes, was up-regulated in the ICC cells transfected with LI-cadherin siRNA. Likewise, PlGF expression was up-regulated in LI-cadherin-negative ICC specimens. There was a significant inverse relationship between these expressions $(\mathrm{P}=0.033)$. Furthermore, the microvessel density of LI-cadherin-negative ICC specimens was higher than that of LI-cadherin-positive specimens. These findings suggest that loss of LI-cadherin in ICC is associated with tumor dedifferentiation and vascular invasion, and thus poor prognosis. Loss of LI-cadherin results in up-regulation of MTF-1 and PlGF, thereby regulating angiogenesis in ICC.

\section{Introduction}

Intrahepatic cholangiocarcinoma (ICC) is the second most common primary liver cancer, and its incidence and mortality have been increasing globally (1-3). Most patients with ICC usually have advanced disease at the time of diagnosis because of the aggressive nature of this tumor, and the 5-year survival rate is only $22-36 \%$ even after curative surgical resection (4). A number of studies have revealed various pathological and biological prognostic factors in ICC, but the precise reason for its biological aggressiveness remains unclear.

Cell-cell adhesion plays pivotal roles in developmental morphogenesis, tissue remodeling and carcinogenesis $(5,6)$. Cell-cell adhesion is strong and stable in normal epithelial cells, whereas in carcinoma cells it is frequently reduced, resulting in destruction of histological structure and allowing carcinoma cells to invade or metastasize. Cadherins constitute 
a superfamily of $\mathrm{Ca}^{2+}$-dependent homotypic cell-cell adhesion molecules that are involved in the maintenance of tissue structure and morphogenesis $(5,7)$. Many members of this superfamily have been identified to date, and are expressed in different tissues in a variety of multicellular organisms. There is increasing evidence that cadherin-mediated cell adhesion plays a critical role in carcinoma cell behavior $(8,9)$.

Liver-intestine cadherin (LI-cadherin), also called HPT-1 (10), is a newly characterized member of the cadherin superfamily distinguished from classic cadherins, such as E- and $\mathrm{N}$-cadherin, by structural and functional features (11). In contrast to classic cadherins, the extracellular domain of LIcadherin consists of seven instead of five structurally defined cadherin repeats. Its cytoplasmic domain is small, comprising only about 20 amino acids, and exhibits no homology with the corresponding region of classic cadherins, which consists of 150-160 amino acids. Like classic cadherins, LI-cadherin possesses adhesive properties, but it is independent of any interaction with catenins or the cytoskeleton (12). We have reported that galectin-3 protein interacted with LI-cadherin protein in pancreatic carcinoma (13), and other investigators have reported that CDX2 protein interacted with the 5'flanking region of the LI-cadherin gene and regulated LIcadherin expression (14). The mechanism responsible for regulation and function of LI-cadherin has been elucidated.

Clinicopathologic significance of LI-cadherin expression has been reported in gastric, colorectal and pancreatic carcinomas (13,15-19). However, the clinicopathologic significance of LI-cadherin expression in ICC has not yet been elucidated, and the potential roles of LI-cadherin in carcinoma are still poorly understood.

In this study, we report that loss of LI-cadherin in ICC is associated with tumor dedifferentiation, venous invasion and poor prognosis. Furthermore, to explore the mechanism underlying the loss of LI-cadherin in ICC aggressiveness, we knocked down LI-cadherin expression in ICC cells using small interfering RNA (siRNA) technology, and screened for genes that were expressed differentially between these cells and ICC cells transfected with scrambled siRNA using microarray analysis. We identified metal-responsive transcription factor-1 (MTF-1) as a gene whose expression was up-regulated in ICC cells transfected with LI-cadherin siRNA. Furthermore, loss of LI-cadherin was found to increase the expression of placental growth factor (PlGF), whose activation is mediated by MTF- 1 , in vitro and in vivo. Our results suggest that loss of LI-cadherin in ICC contributes to promotion of angiogenesis by up-regulating MTF-1 and the subsequent PIGF.

\section{Materials and methods}

Patients and tissue samples. A total of 33 patients with ICCs underwent surgical resection with curative intent at Niigata University Medical and Dental Hospital and its affiliated hospitals during the period between July 1988 and May 2007. Patients with ICCs who received chemotherapy or radiation therapy preoperatively and died within 30 days after their operation were excluded. The median follow-up time was 47.6 months (range, 2-118 months). The gross and pathologic features of ICCs were evaluated according to the classification proposed by the Liver Cancer Study Group in Japan (20), in which ICCs are grossly classified into three macroscopic types: mass-forming (MF) type, periductal infiltrating (PI) type and intraductal growth (IG) type. If more than one type was found, the predominant type was recorded. Macroscopic typing of tumors revealed 25 cases of the MF type, 4 cases of the PI type and 4 cases of the IG type. Although the Liver Cancer Study Group in Japan have classified microscopic vascular invasion into several grades (based on tumor extension), in the present study we categorized it into two grades (i.e., positive or negative). Written informed consent was obtained from each patient (or from their relatives in case of the patient's inability), and the study was approved by the institutional ethics committee.

Cell cultures and antibodies. Two human ICC cell lines (HuH-28 and IHGGK) were obtained from the Cell Resource Center for Biomedical Research (Tohoku University, Sendai, Japan). A human ICC cell line (HuCCT1) was obtained from the Human Science Research Resources Bank (Sennan-shi, Japan). HuH-28 was maintained in MEM medium, whereas IHGGK and HuCCT1 were maintained in RPMI-1640 medium containing $10 \%$ fetal bovine serum and penicillin/ streptomycin (Life Technologies, Inc., Grand Island, NY) in a humidified atmosphere of $5 \% \mathrm{CO}_{2}$ at $37^{\circ} \mathrm{C}$.

A goat polyclonal anti-LI-cadherin antibody (C-17, Santa Cruz Biotechnology Inc., CA) was used for immunoblotting (diluted 1:500) and immunohistochemistry (diluted 1:200). Mouse monoclonal anti-CD34 (clone QBEnd10, Dako, Glostrup, Denmark) and anti-ß-actin (clone AC-15; Sigma Chemical Co., St. Louis, MO) antibodies were used for immunohistochemistry (diluted 1:50) and immunoblotting (diluted 1:5000), respectively. A goat polyclonal anti-PlGF antibody (C-20, Santa Cruz) was used for immunohistochemistry (diluted 1:50).

Immunohistochemistry. Sections (5 $\mu \mathrm{m}$ thick) of formalinfixed, paraffin-embedded tissues were deparaffinized in xylene and rehydrated in ethanol, treated with $0.3 \%$ hydrogen peroxide in methanol, and immersed in citrate buffer (10 mmol/l, $\mathrm{pH}$ 6.0). After autoclaving and preincubation with normal swine serum, the sections were incubated with primary antibodies at $4^{\circ} \mathrm{C}$ overnight, followed sequentially by the biotinylated secondary antibody and avidin-biotinperoxidase complex using a Vectastain ABC kit (Vector Laboratories, Burlingame, CA). The reaction products were visualized using $0.05 \%$ diaminobenzidine tetrahydrochloride solution containing $0.01 \%$ hydrogen peroxide, and counterstaining was done with hematoxylin. Negative control staining was performed using the same class of goat and mouse immunoglobulin instead of the primary antibodies.

Assessment of LI-cadherin expression and microvessel density. The LI-cadherin expression of the tumor cells was evaluated according to the proportion of tumor cells that showed positive immunoreactivity on the cell membrane. Staining was considered positive when more than $10 \%$ of the tumor cell membrane was positively stained. When fewer than $10 \%$ of the tumor cells were positively stained, the staining was considered negative. 
The degree of angiogenesis was determined by the number of CD34-positive microvessels in defined areas of tumor sections according to a method of Weidner et al (21). The highly vascular areas (hot spots) were identified by scanning tumor sections at low magnification (x40 or $\mathrm{x} 100)$. The number of CD34-positive microvessels was counted in five selected hot spots at high magnification (x200) and the median was taken as the microvessel density (MVD) of the tumor section. All the hematoxylin and eosin-stained and immunohistochemistry slides were assessed by two independent observers who had no knowledge of the patients' clinicopathologic information.

Immunoblotting. Protein samples were prepared, and immunoblotting was carried out as described previously (13). In brief, $50 \mu \mathrm{g}$ of protein was electrophoresed on sodium dodecyl sulfate polyacrylamide gels and transferred to Immobilon membranes (Millipore, Bedford, MA). After blocking, the filter was reacted with primary antibodies followed by the horseradish peroxidase-conjugated secondary antibodies (GE Healthcare, Piscataway, NJ). Peroxidase-labeled bands were visualized with the ECL detection reagents (GE Healthcare) in accordance with the manufacturer's instructions. For confirmation of equal loading, the blots were reprobed with anti- $\beta$-actin antibody.

Small interfering RNA transfection. For silencing LI-cadherin gene expression, the following siGENOME on-target duplexes (Dharmacon, Inc., Lafayette, CO) were used: J-011829-06 [LI-cadherin-siRNA-1, UCAAGCAUCUGAAGUCAAAUU (sense)] and J-011829-07 [LI-cadherin-siRNA-2, GAA CCGAGUCAAAUUAUAUUU (sense)]. Scrambled siRNA (Dharmacon) was used as a control. IHGGK cells were seeded into $60-\mathrm{mm}$ dishes for $24 \mathrm{~h}$ at about $70 \%$ confluence, and then transfection of siRNA was performed using DharmaFECT 1 transfection reagent (Dharmacon) in accordance with the manufacturer's protocol. Forty-eight (mRNA) or 72 (protein) hours after transfection, RNA and protein were extracted for real-time polymerase chain reaction $(\mathrm{PCR})$ and immunoblotting, respectively.

Microarray analysis. IHGGK cells were transfected with scrambled siRNA or LI-cadherin siRNA-1. We chose $48 \mathrm{~h}$ after transfection as our optimal treatment time for microarray analysis because the LI-cadherin mRNA level was maximally knocked down at $48 \mathrm{~h}$ after transfection with LIcadherin siRNA (data not shown). Cells were collected $48 \mathrm{~h}$ after transfection, and RNA was isolated using an RNeasy Mini kit (Qiagen, Valencia, CA). Microarray analysis was performed using a GeneChip Human Genome U133 Plus 2.0 Array (Affymetrix, Santa Clara, CA) representing 38,500 genes. Samples were processed into cRNA, hybridized to chips, and scanned at the Takara Bio Dragon Genomics Center (Mie, Japan). The expression data were analyzed using Affymetrix GeneChip Operating Software version 1.4.

Real-time PCR analysis. Total RNA was isolated using the RNeasy Mini kit in accordance with the manufacturer's protocol. cDNA was synthesized using $6 \mu \mathrm{g}$ of total RNA using a PrimeScript RT reagent kit (Takara Bio, Otsu, Japan).
Aliquots of cDNA samples were subjected to real-time PCR using a LightCycler System (Roche). The TaqMan probe and primer sets for human LI-cadherin (assay identification number Hs00184865_m1), MTF-1 (assay identification number Hs00232306_m1), vascular endothelial growth factor (VEGF)-A (assay identification number Hs00900054_m1), VEGF-B (assay identification number Hs00173634_m1), VEGF-C (assay identification number Hs00153458_m1), VEGF-D (assay identification number Hs00189521_m1) and PlGF (assay identification number Hs00182176_m1) were TaqMan Gene Expression Assays (Applied Biosystems, Foster City, CA). PCR conditions were: $95^{\circ} \mathrm{C}$ for $10 \mathrm{~min}$, and 45 cycles of $95^{\circ} \mathrm{C}$ for $10 \mathrm{sec}, 60^{\circ} \mathrm{C}$ for $30 \mathrm{sec}$, and $72^{\circ} \mathrm{C}$ for $1 \mathrm{sec}$. The results were normalized by the levels of mRNA for human glyceraldehyde-3-phosphate dehydrogenase (GAPDH). Gene expression measurements were performed in triplicate.

Statistical analysis. Statistical analyses were performed using SPSS version 15.0 for Windows (SPSS, USA). Continuous variables were expressed as means \pm standard deviation or median (range). Expression of LI-cadherin was assessed for associations with various clinicopathological parameters using the Chi-square test or Fisher's exact test. Survival rates were calculated by the Kaplan-Meier method. The difference between the survival curves was analyzed by the log-rank test. Univariate and backward stepwise multivariate survival analyses were performed using the Cox proportional hazards model. Comparison of continuous variables between two independent groups was analyzed by Student's t-test or Mann-Whitney U test when appropriate. Differences were considered to be significant when the P-value was $<0.05$.

\section{Results}

LI-cadherin expression in non-neoplastic biliary epithelium and intrahepatic cholangiocarcinoma. Expression of LIcadherin was examined by immunohistochemistry in 34 patients with ICC. LI-cadherin was not expressed in nonneoplastic biliary epithelium (Fig. 1A). In ICC, many tumor cells of well-differentiated carcinoma nests expressed LIcadherin strongly (Fig. 1B). However, reduced or loss of LIcadherin expression was observed in many tumor cells in the less differentiated carcinoma nests (Fig. 1C).

\section{Relationship between LI-cadherin expression and clinico-} pathological parameters. According to our criteria described in Materials and methods, 18 (52.9\%) of the 34 cases were classified as having positive LI-cadherin expression, whereas the remaining $16(47.1 \%)$ were classified as having negative LI-cadherin expression. Table I summarizes the relationship between the extent of LI-cadherin expression and various clinicopathological parameters. There was a significant relationship between vascular invasion and negative LIcadherin expression $(\mathrm{P}=0.037)$ or high histological grade (moderately or poorly differentiated carcinomas) and negative LI-cadherin expression $(\mathrm{P}=0.030)$.

Survival analysis. Survival analysis according to the KaplanMeier method revealed that patients whose tumors were LI- 

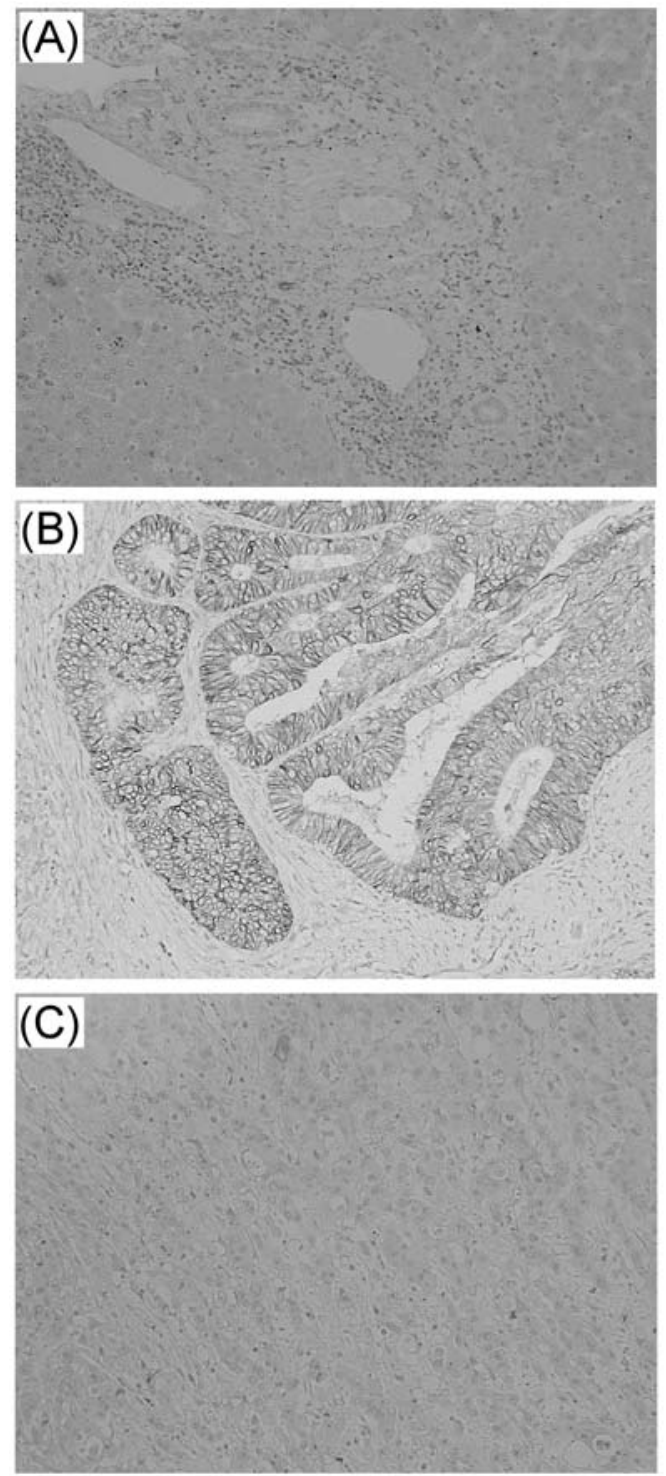

Figure 1. Expression of LI-cadherin in non-neoplastic biliary epithelium and intrahepatic cholangiocarcinoma. (A) LI-cadherin was absent in nonneoplastic biliary epithelium. LI-cadherin was expressed strongly in welldifferentiated carcinoma nests (B), but less so in dedifferentiated carcinoma nests (C). Original magnification, x200.

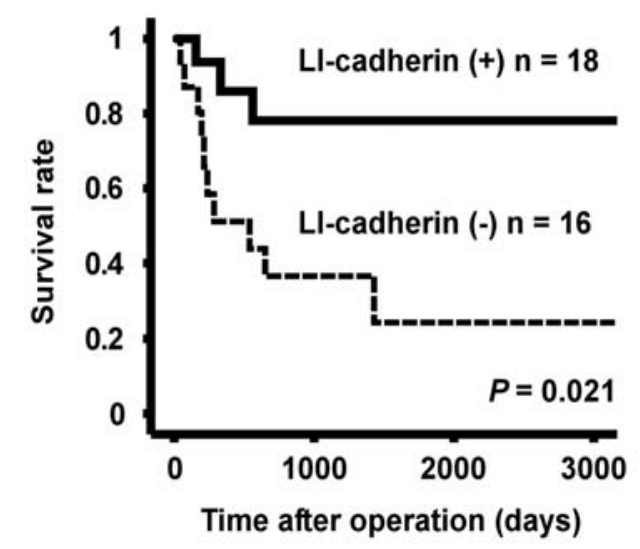

Figure 2. Kaplan-Meier survival curves for overall survival according to LIcadherin expression in 34 patients with intrahepatic cholangiocarcinoma. The prognosis became significantly worse in the group with negative LIcadherin expression (dashed line) than in the group with positive expression (solid line; log-rank test, $\mathrm{P}=0.021$ ).

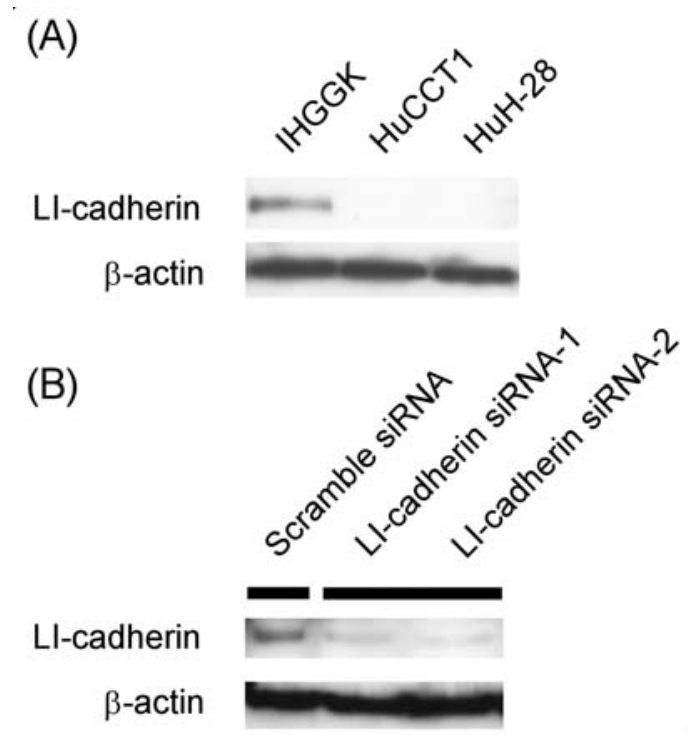

Figure 3. Expression of LI-cadherin in human intrahepatic cholangiocarcinoma cell lines. (A) Three human intrahepatic cholangiocarcinoma cell lines were assessed by immunoblotting for the expression of LI-cadherin. (B) Down-regulation of LI-cadherin protein expression induced by LIcadherin siRNA-1, -2 in IHGGK cells. These membranes were reblotted with a monoclonal antibody against $\beta$-actin as a control.

cadherin-negative had a significantly shorter overall survival time than those with LI-cadherin-positive tumors $(\mathrm{P}=0.021$, log-rank test, Fig. 2). The 1-, 3- and 5-year survival rates were $51.1,36.5$ and $24.4 \%$ in the patients with LI-cadherinnegative tumors, compared with $85.9,78.1$ and $78.1 \%$ in those with LI-cadherin-positive tumors, respectively.

The univariate analysis of prognostic parameters of ICC is summarized in Table II. High histological grade $(\mathrm{P}=0.047)$, lymph node metastasis $(\mathrm{P}=0.013)$, surgical margin $(\mathrm{P}=0.032)$ and the extent of LI-cadherin staining $(\mathrm{P}=0.030)$ were statistically significant risk factors affecting outcome in patients with ICC. The prognostic parameters were analyzed using backward stepwise multivariate analysis. Lymph node metastasis $(\mathrm{P}=0.013$; hazard ratio $5.160,95 \%$ confidence interval 1.422-18.716) and the extent of LI-cadherin staining $(\mathrm{P}=0.027$; hazard ratio $3.778,95 \%$ confidence interval 1.164 12.264) were independent prognostic parameters (Table III).

Expression of LI-cadherin in ICC cell lines. We examined the expression of LI-cadherin in the three ICC cell lines by immunoblotting. LI-cadherin expression was detected only in IHGGK cells, and not in HuCCT1 or HuH-28 cells (Fig. 3A). Likewise, real-time PCR analysis showed that LI-cadherin mRNA was expressed only in IHGGK cells (data not shown). Therefore, we selected IHGGK cells for further investigation.

Metal-responsive transcription factor-1 gene expression is up-regulated by LI-cadherin siRNA transfection. To determine the role of LI-cadherin in ICC, we used the RNA interference strategy to knock down the molecule, and screened for genes that were expressed differentially between the IHGGK cells transfected with LI-cadherin siRNA and those transfected with scrambled siRNA using microarray analysis. Real-time PCR analysis showed that the LI-cadherin mRNA level was knocked down $24 \mathrm{~h}$ after transfection with 
Table I. Relationship between clinicopathologic parameters and LI-cadherin expression in patients with intrahepatic cholangiocarcinoma.

\begin{tabular}{|c|c|c|c|c|}
\hline \multirow[b]{2}{*}{ Variable } & \multirow{2}{*}{$\begin{array}{l}\text { Number } \\
\text { of cases }\end{array}$} & \multicolumn{2}{|c|}{ LI-cadherin expression } & \multirow[b]{2}{*}{$\mathrm{P}$-value } \\
\hline & & Positive & Negative & \\
\hline \multicolumn{5}{|l|}{ Age (years) } \\
\hline$\leq 65$ & 14 & 7 & 7 & \multirow[t]{2}{*}{$>0.999$} \\
\hline$>65$ & 20 & 11 & 9 & \\
\hline \multicolumn{5}{|l|}{ Gender } \\
\hline Male & 23 & 12 & 11 & \multirow[t]{2}{*}{$>0.999$} \\
\hline Female & 11 & 6 & 5 & \\
\hline \multicolumn{5}{|l|}{ Tumor size $(\mathrm{cm})$} \\
\hline$<4.5$ & 15 & 8 & 7 & \multirow[t]{2}{*}{$>0.999$} \\
\hline$\geq 4.5$ & 19 & 10 & 9 & \\
\hline \multicolumn{5}{|l|}{ Growth morphology } \\
\hline MF type & 26 & 13 & 13 & \multirow[t]{2}{*}{0.693} \\
\hline PI or IG type & 8 & 5 & 3 & \\
\hline \multicolumn{5}{|l|}{ Histological grade } \\
\hline Well & 11 & 9 & 2 & \multirow[t]{2}{*}{0.030} \\
\hline Moderately or poorly & 23 & 9 & 14 & \\
\hline \multicolumn{5}{|l|}{ Vascular invasion } \\
\hline Negative & 18 & 13 & 5 & \multirow{2}{*}{0.037} \\
\hline Positive & 16 & 5 & 11 & \\
\hline \multicolumn{5}{|l|}{ Lymphatic invasion } \\
\hline Negative & 14 & 9 & 5 & \multirow[t]{2}{*}{0.315} \\
\hline Positive & 20 & 9 & 11 & \\
\hline \multicolumn{5}{|l|}{ Lymph node metastasis } \\
\hline Negative & 25 & 14 & 11 & \multirow[t]{2}{*}{0.703} \\
\hline Positive & 9 & 4 & 5 & \\
\hline \multicolumn{5}{|l|}{ Intrahepatic metastasis } \\
\hline Negative & 27 & 15 & 12 & \multirow[t]{2}{*}{0.681} \\
\hline Positive & 7 & 3 & 4 & \\
\hline \multicolumn{5}{|l|}{ Surgical margin } \\
\hline Negative & 24 & 14 & 10 & \multirow{2}{*}{0.457} \\
\hline Positive & 10 & 4 & 6 & \\
\hline
\end{tabular}

${ }^{a} \mathrm{MF}$, mass-forming; PI, periductal infiltrating; IG, intraductal growth.

LI-cadherin siRNA-1 and -2 (data not shown). Likewise, immunoblotting showed that the LI-cadherin protein level was knocked down $72 \mathrm{~h}$ after transfection with LI-cadherin siRNA-1 and -2 (Fig. 3B). We found 21 genes that were differentially expressed ( $\geq 2$-fold change) between the IHGGK cells transfected with LI-cadherin siRNA and those transfected with scrambled siRNA using microarray analysis (attached table in Fig. 4). Among these genes, 12 were upregulated and 9 were down-regulated in the IHGGK cells transfected with LI-cadherin siRNA relative to those transfected with scrambled siRNA. We confirmed that the expression of LI-cadherin was down-regulated, as expected (attached table in Fig. 4). On the basis of the results of immunohistochemical analysis, we selected several genes that could have the potential to increase tumor aggressiveness. We then performed real-time PCR analyses to confirm the results of microarray analysis, and found that $M T F-1$ gene expression was reproducibly up-regulated in LI-cadherin siRNAtransfected IHGGK cells $(\mathrm{P}<0.01$; Fig. 4).

Loss of LI-cadherin induces angiogenesis by increasing placental growth factor expression in ICC. It has been reported that MTF-1 is involved in the transcriptional regulation of the PlGF gene, a member of the VEGF family of 
Table II. Univariate analysis of prognostic factors.

\begin{tabular}{lc}
\hline Variable & $\begin{array}{l}\text { Num } \\
\text { of case }\end{array}$ \\
\hline Age (years) & \\
$\leq 65$ & 1 \\
$>65$ & 20
\end{tabular}

Gender

Male

Female

Number

of cases

14

20

1.429

$0.477-4.284$

0.524

0.824

$0.251-2.705$

0.750

Tumor size $(\mathrm{cm})$

$<4.5$

$\geq 4.5$

15

19

0.448

0.154-1.302

0.140

Growth morphology ${ }^{\mathrm{a}}$

MF type

PI or IG type

26

8

0.814

$0.247-2.688$

0.736

Histological grade

Well

Moderately or poorly

11

23

4.761

1.022-22.172

0.047

Vascular invasion

Negative

18

Positive

16

2.323

0.733-7.367

0.152

Lymphatic invasion

Negative

14

Positive

20

1.364

0.469-3.968

0.569

Lymph node metastasis

Negative

Positive

25

9

1

4.711

1.391-15.948

0.013

Intrahepatic metastasis

Negative

Positive

0.769-8.281

0.127

Surgical margin

Negative

Positive

11

3.548

$1.118-11.262$

0.032

LI-cadherin expression

Positive

Negative

18

16

3.617

$1.130-11.577$

0.030

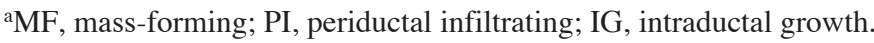

Table III. Stepwise multivariate analysis of prognostic factors.

\begin{tabular}{lcccc}
\hline Variable & $\begin{array}{c}\text { Number } \\
\text { of cases }\end{array}$ & Hazard ratio & $\begin{array}{c}\text { 95\% Confidence } \\
\text { interval }\end{array}$ & \\
\hline $\begin{array}{l}\text { Lymph node metastasis } \\
\quad \text { Negative }\end{array}$ & 25 & 1 & & \\
$\quad$ Positive & 9 & 5.160 & $1.422-18.716$ & \\
LI-cadherin expression & 18 & 1 & & \\
$\quad$ Positive & 16 & 3.778 & $1.164-12.264$ & 0.027 \\
$\quad$ Negative & & & & \\
\hline
\end{tabular}




\begin{tabular}{|c|c|c|}
\hline $\begin{array}{c}\text { Accession } \\
\text { No. }\end{array}$ & $\begin{array}{c}\text { Gene } \\
\text { Symbol }\end{array}$ & $\begin{array}{c}\text { Gene } \\
\text { Description }\end{array}$ \\
\hline $\begin{array}{l}<\text { Up-regulat } \\
\text { AJ457067 } \\
\text { AJ261321 } \\
\text { NM_002562 } \\
\text { NM_013357 } \\
\text { X90539 } \\
\text { AU145127 } \\
\text { NM_005509 } \\
\text { NM_001148 } \\
\text { NM_152577 } \\
\text { AK098841 } \\
\text { NM_005955 } \\
\text { M96789 }\end{array}$ & $\begin{array}{l}\text { KRTAP19-1 } \\
\text { KRAM2A } \\
\text { FARX7 } \\
\text { PURG } \\
\text { TRIM10 } \\
\text { FBXL7 } \\
\text { DMXL1 } \\
\text { ANK2 } \\
\text { ZNF645 } \\
\text { VWA3B } \\
\text { MTF1 } \\
\text { GJA4 }\end{array}$ & $\begin{array}{l}\text { keratin associated protein } 19-1 \\
\text { family with sequence similarity } 82 \text {, member } A \\
\text { purinergic receptor } P 2 X \\
\text { purine-rich element binding protein } G \\
\text { tripartite motif-containing } 10 \\
\text { F-box and leucine-rich repeat protein } 7 \\
\text { Dmx-like } 1 \\
\text { ankyrin } 2 \text {, neuronal } \\
\text { zinc finger protein } 645 \\
\text { von Willebrand factor } A \text { domain containing } 3 B \\
\text { metal-regulatory transcription factor } 1 \\
\text { gap junction protein, alpha } 4,37 \mathrm{kDa}\end{array}$ \\
\hline $\begin{array}{l}\text { <Down-regl } \\
\text { U07969 } \\
\text { X95152 } \\
\text { NM_004703 } \\
\text { N76327 } \\
\text { AU148039 } \\
\text { AL575584 } \\
\text { BC002665 } \\
\text { NM_032202 } \\
\text { BC } 006370\end{array}$ & $\begin{array}{l}\text { ted> } \\
\text { CDH17 } \\
\text { BRCA2 } \\
\text { RABEP1 } \\
\text { TFRC } \\
\text { GPR144 } \\
\text { TMEM67 } \\
\text { PLP1 } \\
\text { KIAA1109 } \\
\text { INVS }\end{array}$ & $\begin{array}{l}\text { LI-cadherin } \\
\text { breast cancer 2, early onset } \\
\text { rabaptin, RAB GTPase binding effector protein } 1 \\
\text { transferrin receptor ( } \mathrm{p} 90, \mathrm{CD} 71 \text { ) } \\
\mathrm{G} \text { protein-coupled receptor } 144 \\
\text { transmembrane protein } 67 \\
\text { proteolipid protein } 1 \\
\text { KIAA1109 } \\
\text { inversin }\end{array}$ \\
\hline
\end{tabular}

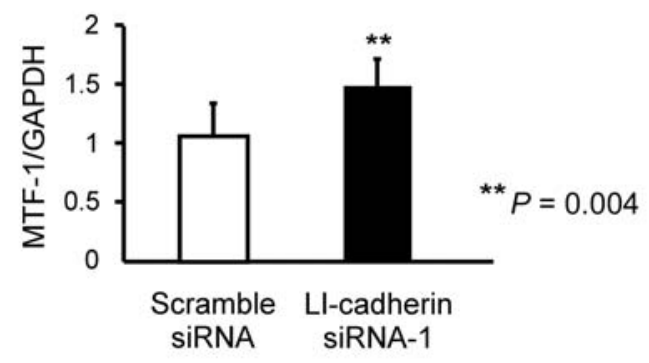

Figure 4. Microarray analysis of IHGGK cells transfected with LI-cadherin siRNA. Twenty-one genes displayed a two-fold or more increase or decrease in expression level (top). Metal-responsive transcription factor-1 mRNA in IHGGK cells transfected with LI-cadherin siRNA and with scrambled siRNA was measured by real-time PCR analysis (bottom).

proangiogenic factors (22). We therefore investigated whether VEGF family members were up-regulated in the IHGGK cells transfected with LI-cadherin siRNA. We found that PIGF mRNA levels were significantly up-regulated only in the IHGGK cells transfected with LI-cadherin siRNA $(\mathrm{P}<0.05$; Fig. 5). Next, to assess the degree of angiogenesis in ICC specimens, we determined MVD in the tumors by immunostaining for CD34. The MVD was significantly higher in LI-cadherin-negative tumors (median, 80.1; range, 51.2-115.4) than in LI-cadherin-positive ones (median, 33.2; range, 21.6-84.4) $(\mathrm{P}<0.01$; Fig. 6). Finally, we investigated the relationship between LI-cadherin and PlGF protein expression by immunohistochemistry using serial tissue sections from ICC specimens. PlGF expression was upregulated in LI-cadherin-negative ICC specimens (Fig. 7). There was a significant inverse relationship between LIcadherin and PlGF expression $(\mathrm{P}=0.033$; attached table in Fig. 7).

\section{Discussion}

We and other groups have investigated LI-cadherin expression immunohistochemically in several human carcinomas. Interestingly, the pattern of LI-cadherin expression differed among tumors of different types. Reduced expression of LIcadherin was associated with tumor progression and aggres- siveness in pancreatic and colorectal carcinomas $(13,18,19)$, whereas overexpression of LI-cadherin was associated with tumor progression and aggressiveness in almost all gastric carcinomas $(15,16)$. However, the clinicopathological and biological significance of LI-cadherin expression in ICC has not been investigated previously.

In the present study, we demonstrated that LI-cadherin was strongly expressed in the plasma membrane of many well-differentiated cases, and that its expression was significantly decreased and less intense, or even absent, in many moderately to poorly differentiated cases, although it was absent in non-neoplastic biliary epithelium. These observations suggest that LI-cadherin is not relevant to the maintenance of normal morphology and polarity of nonneoplastic biliary epithelium, whereas it is relevant to the maintenance of architectural preservation of ICC.

The present clinicopathological study demonstrated that negative LI-cadherin expression was associated with dedifferentiation and vascular invasion. Moreover, LI-cadherin negativity was an independent factor indicative of poor prognosis in ICCs. These findings suggest that loss of LIcadherin may contribute to dedifferentiation and vascular invasion of ICC, thereby resulting in a worse prognosis.

To clarify how loss of LI-cadherin influences the aggressiveness of ICC, we performed microarray analysis on the LI-cadherin-positive IHGGK cell line subjected or not to 

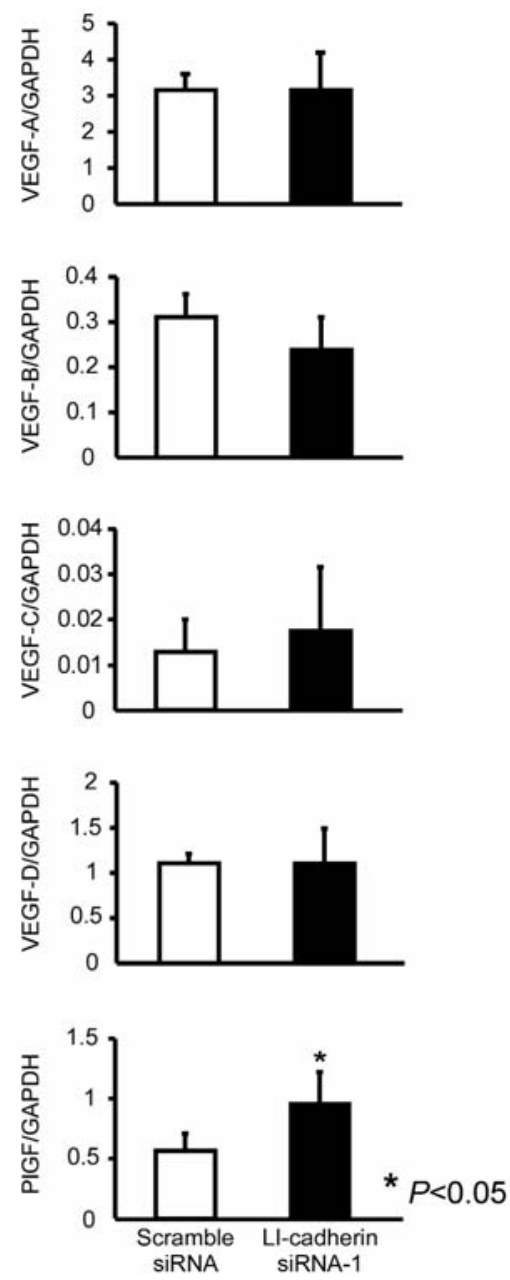

Figure 5. Loss of LI-cadherin induces angiogenesis by increasing the expression of placental growth factor in intrahepatic cholangiocarcinoma. Effects of LI-cadherin knockdown on expression of VEGF-A, VEGF-B, VEGF-C, VEGF-D and PIGF were examined by real-time PCR analysis. Glyceraldehyde-3-phosphate dehydrogenase (GAPDH) served as control.

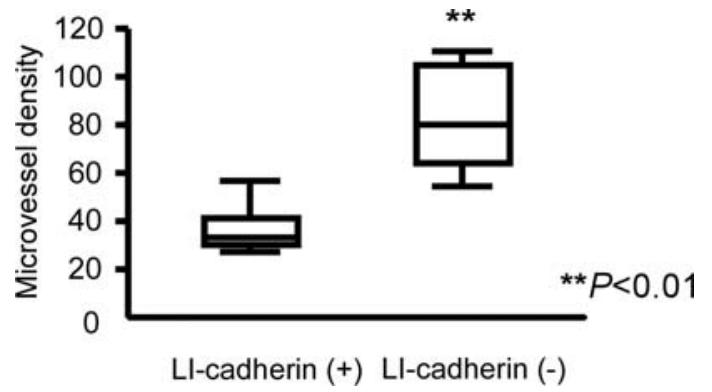

Figure 6. Relationship between LI-cadherin expression and microvessel density obtained by staining for CD34, and analyzed by Mann-Whitney U test.

LI-cadherin knockdown via siRNA. Among the genes we identified, some were previously reported to be altered in human cancers. For example, purinergic receptor P2X was overexpressed in several carcinomas $(23,24)$. We found that MTF-1 was up-regulated by LI-cadherin siRNA transfection. MTF-1 is a highly conserved, ubiquitous protein that responds to various environmental stresses including exposure to heavy metals, hypoxia and oxidative stress (25). Targeted disruption of the MTF- 1 gene in the mouse resulted in lethal liver degeneration on day 14 of gestation (26), while in ras-transformed mouse embryonic fibroblasts, loss of MTF-1 resulted in suppressed tumor growth associated with increased matrix deposition and decreased tumor angiogenesis (27). The several MTF-1 target genes identified to date include genes that function in apoptosis resistance, invasion and angiogenesis, all of which might contribute to tumor aggressiveness $(22,28,29)$. Based on the immunohistochemical results, we focused on PIGF, one of the MTF-1 target genes, for further testing.

$\mathrm{PlGF}$ is a secreted dimeric glycoprotein that shares close amino acid sequence homology (53\%) with VEGF (30).

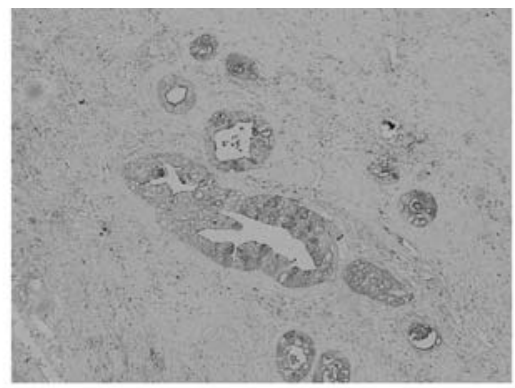

PIGF

\begin{tabular}{ccccc}
\hline & \multicolumn{3}{c}{ PIGF expression* } & \\
\cline { 2 - 4 } & Negative $(n=6)$ & Weakly $(n=19)$ & Strong $(n=9)$ & \\
\hline LI-cadherin expression & & & & \\
\hline Positive $(n=18)$ & 5 & 11 & 2 & 0.033 \\
Negative $(n=16)$ & 1 & 8 & 7 & \\
\hline
\end{tabular}

"Negative, $<10 \%$ of cells positive; Weakly, $10 \%$ to $50 \%$ positive; Strongly, $>50 \%$ positive. †Mann-Whitney $U$ test.

Figure 7. (Top) Representative immunohistochemical staining for LI-cadherin and PIGF in intrahepatic cholangiocarcinoma tissue (serial sections). Original magnification, x100. (Bottom) Correlation between LI-cadherin and PIGF expression in 34 cases of intrahepatic cholangiocarcinoma. 
Genetic studies showed that absence of $P l G F$ had a negligible effect on embryonic angiogenesis, whereas it impaired angiogenesis and plasma extravasation in pathological conditions, including ischemia, inflammation and cancer (31). There is increasing evidence that PIGF expression is correlated with tumor stage, vascularity, recurrence, metastasis and patient survival in various human cancers (32-36). A recent study using microarray and immunohistochemical analyses has shown that PlGF expression is relatively higher in Japanese ICCs (non-liver fluke-associated) than in Thai ICCs (liver fluke-associated) (37). We found that, among the VEGF family, PIGF mRNA levels were significantly up-regulated only in IHGGK cells transfected with LI-cadherin siRNA. Indeed, PlGF protein expression was increased in LIcadherin-negative ICCs, and the MVD was 2.4-fold higher in LI-cadherin-negative ICCs. These findings suggest that loss of LI-cadherin in ICC contributes to angiogenesis by upregulating MTF-1, and subsequently PlGF. PlGF amplifies VEGF-driven angiogenesis via cross-talk between VEGFR-1 and VEGFR-2 to form new blood vessels in endothelial cells in many pathological conditions (31). In addition, several studies have reported that VEGF expression is highly abundant in ICC tissues (38-40). Although we did not examine the effects of PIGF and/or VEGF on endothelial cells, we speculate that synergism between PIGF and VEGF promotes angiogenesis in LI-cadherin-negative ICCs. Further investigations are required to clarify the mechanism of loss of LI-cadherin-induced angiogenesis.

In summary, we have found that loss of LI-cadherin is closely associated with tumor dedifferentiation and vascular invasion in ICC, leading to poor prognosis. We have provided mechanistic evidence that loss of LI-cadherin results in up-regulation of MTF-1, and subsequently PIGF, thereby regulating angiogenesis in ICC. Regulation of LIcadherin expression shows promise for prevention of angiogenesis in ICC.

\section{Acknowledgements}

This work was supported by Grant for Promotion of Niigata University Research Projects and Grant-in-Aid for Young Scientists (B) (No. 19790473) from the Ministry of Education, Culture, Sports, Science and Technology of Japan.

\section{References}

1. Patel T: Increasing incidence and mortality of primary intrahepatic cholangiocarcinoma in the United States. Hepatology 33: 1353-1357, 2001.

2. Taylor-Robinson SD, Toledano MB, Arora S, et al: Increase in mortality rates from intrahepatic cholangiocarcinoma in England and Wales 1968-1998. Gut 48: 816-820, 2001.

3. Okuda K, Nakanuma Y and Miyazaki M: Cholangiocarcinoma: recent progress. Part 1: epidemiology and etiology. J Gastroenterol Hepatol 17: 1049-1055, 2002.

4. Jarnagin WR and Shoup M: Surgical management of cholangiocarcinoma. Semin Liver Dis 24: 189-199, 2004.

5. Takeichi M: Morphogenetic roles of classic cadherins. Curr Opin Cell Biol 7: 619-627, 1995.

6. Gumbiner BM: Cell adhesion: the molecular basis of tissue architecture and morphogenesis. Cell 84: 345-357, 1996.

7. Ranscht B: Cadherins and catenins: interactions and functions in embryonic development. Curr Opin Cell Biol 6: 740-746, 1994.

8. Takeichi M: Cadherins in cancer: implications for invasion and metastasis. Curr Opin Cell Biol 5: 806-811, 1993.
9. Hirohashi S: Inactivation of the E-cadherin-mediated cell adhesion system in human cancers. Am J Pathol 153: 333-339, 1998.

10. Dantzig AH, Hoskins JA, Tabas LB, et al: Association of intestinal peptide transport with a protein related to the cadherin superfamily. Science 264: 430-433, 1994.

11. Gessner $\mathrm{R}$ and Tauber R: Intestinal cell adhesion molecules. Liver-intestine cadherin. Ann NY Acad Sci 915: 136-143, 2000.

12. Kreft B, Berndorff D, Bottinger A, et al: LI-cadherin-mediated cell-cell adhesion does not require cytoplasmic interactions. J Cell Biol 136: 1109-1121, 1997.

13. Takamura M, Sakamoto M, Ino Y, et al: Expression of liverintestine cadherin and its possible interaction with galectin-3 in ductal adenocarcinoma of the pancreas. Cancer Sci 94: 425-430, 2003.

14. Hinoi T, Lucas PC, Kuick R, Hanash S, Cho KR and Fearon ER: $\mathrm{CDX} 2$ regulates liver intestine-cadherin expression in normal and malignant colon epithelium and intestinal metaplasia. Gastroenterology 123: 1565-1577, 2002.

15. Ko S, Chu KM, Luk JM, et al: Overexpression of LI-cadherin in gastric cancer is associated with lymph node metastasis. Biochem Biophys Res Commun 319: 562-568, 2004.

16. Ito R, Oue N, Yoshida K, et al: Clinicopathological significant and prognostic influence of cadherin-17 expression in gastric cancer. Virchows Arch 447: 717-722, 2005.

17. Grotzinger C, Kneifel J, Patschan D, et al: LI-cadherin: a marker of gastric metaplasia and neoplasia. Gut 49: 73-81, 2001.

18. Takamura M, Ichida T, Matsuda Y, et al: Reduced expression of liver-intestine cadherin is associated with progression and lymph node metastasis of human colorectal carcinoma. Cancer Lett 212: 253-259, 2004.

19. Kwak JM, Min BW, Lee JH, et al: The prognostic significance of E-cadherin and liver intestine-cadherin expression in colorectal cancer. Dis Colon Rectum 50: 1873-1880, 2007.

20. Liver Cancer Study Group of Japan: The General rules for the clinical and pathological study of primary liver cancer. 2nd English edition. Kanehara, Tokyo, pp16-17, 2004.

21. Weidner N, Semple JP, Welch WR and Folkman J: Tumor angiogenesis and metastasis - correlation in invasive breast carcinoma. N Engl J Med 324: 1-8, 1991.

22. Green CJ, Lichtlen P, Huynh NT, et al: Placenta growth factor gene expression is induced by hypoxia in fibroblasts: a central role for metal transcription factor-1. Cancer Res 61: 2696-2703, 2001.

23. Solini A, Cuccato S, Ferrari D, et al: Increased $\mathrm{P} 2 \mathrm{X} 7$ receptor expression and function in thyroid papillary cancer: a new potential marker of the disease? Endocrinology 149: 389-396, 2008.

24. Slater M, Danieletto S, Gidley-Baird A, Teh LC and Barden JA: Early prostate cancer detected using expression of non-functional cytolytic P2X7 receptors. Histopathology 44: 206-215, 2004.

25. Laity JH, Andrews GK: Understanding the mechanisms of zincsensing by metal-response element binding transcription factor-1 (MTF-1). Arch Biochem Biophys 463: 201-210, 2007.

26. Gunes C, Heuchel R, Georgiev O, et al: Embryonic lethality and liver degeneration in mice lacking the metal-responsive transcriptional activator MTF-1. EMBO J 17: 2846-2854, 1998.

27. Haroon ZA, Amin K, Lichtlen P, et al: Loss of metal transcription factor- 1 suppresses tumor growth through enhanced matrix deposition. FASEB J 18: 1176-1184, 2004.

28. Murphy BJ: Regulation of malignant progression by the hypoxia-sensitive transcription factors HIF-1alpha and MTF-1. Comp Biochem Physiol B Biochem Mol Biol 139: 495-507, 2004.

29. Kang YJ, Zhou ZX, Wang GW, Buridi A and Klein JB: Suppression by metallothionein of doxorubicin-induced cardiomyocyte apoptosis through inhibition of p38 mitogenactivated protein kinases. J Biol Chem 275: 13690-13698, 2000.

30. Maglione D, Guerriero V, Viglietto G, Delli-Bovi P and Persico MG: Isolation of a human placenta cDNA coding for a protein related to the vascular permeability factor. Proc Natl Acad Sci USA 88: 9267-9271, 1991.

31. Carmeliet P, Moons L, Luttun A, et al: Synergism between vascular endothelial growth factor and placental growth factor contributes to angiogenesis and plasma extravasation in pathological conditions. Nat Med 7: 575-583, 2001. 
32. Matsumoto K, Suzuki K, Koike H, et al: Prognostic significance of plasma placental growth factor levels in renal cell cancer: an association with clinical characteristics and vascular endothelial growth factor levels. Anticancer Res 23: 4953-4958, 2003.

33. Chen CN, Hsieh FJ, Cheng YM, et al: The significance of placenta growth factor in angiogenesis and clinical outcome of human gastric cancer. Cancer Lett 213: 73-82, 2004.

34. Parr C, Watkins G, Boulton M, Cai J and Jiang WG: Placenta growth factor is over-expressed and has prognostic value in human breast cancer. Eur J Cancer 41: 2819-2827, 2005.

35. Wei SC, Tsao PN, Yu SC, et al: Placenta growth factor expression is correlated with survival of patients with colorectal cancer. Gut 54: 666-672, 2005.

36. Ho MC, Chen CN, Lee H, et al: Placenta growth factor not vascular endothelial growth factor $\mathrm{A}$ or $\mathrm{C}$ can predict the early recurrence after radical resection of hepatocellular carcinoma. Cancer Lett 250: 237-249, 2007.
37. Jinawath N, Chamgramol Y, Furukawa Y, et al: Comparison of gene expression profiles between Opisthorchis viverrini and non-Opisthorchis viverrini associated human intrahepatic cholangiocarcinoma. Hepatology 44: 1025-1038, 2006.

38. Benckert C, Jonas S, Cramer T, et al: Transforming growth factor beta 1 stimulates vascular endothelial growth factor gene transcription in human cholangiocellular carcinoma cells. Cancer Res 63: 1083-1092, 2003.

39. Tang D, Nagano H, Yamamoto $\mathrm{H}$, et al: Angiogenesis in cholangiocellular carcinoma: expression of vascular endothelial growth factor, angiopoietin-1/2, thrombospondin-1 and clinicopathological significance. Oncol Rep 15: 525-532, 2006.

40. Yoshikawa D, Ojima H, Iwasaki M, et al: Clinicopathological and prognostic significance of EGFR, VEGF, and HER2 expression in cholangiocarcinoma. Br J Cancer 98: 418-425, 2008. 